\title{
Photocatalyic Appel reaction enabled by copper-based complexes in continuous flow
}

\author{
Clémentine Minozzi, Jean-Christophe Grenier-Petel, Shawn Parisien-Collette \\ and Shawn K. Collins*
}

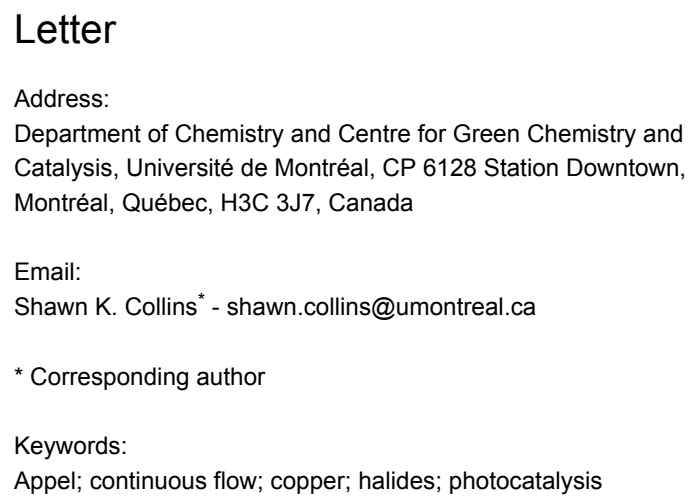

\author{
Beilstein J. Org. Chem. 2018, 14, 2730-2736. \\ doi:10.3762/bjoc. 14.251
}

Received: 09 July 2018

Accepted: 12 October 2018

Published: 30 October 2018

This article is part of the thematic issue "Reactive intermediates part I: radicals".

Guest Editor: T. P. Yoon

(c) 2018 Minozzi et al.; licensee Beilstein-Institut.

License and terms: see end of document.

\begin{abstract}
A copper-based photocatalyst, $\mathrm{Cu}(\mathrm{tmp})(\mathrm{BINAP}) \mathrm{BF}_{4}$, was found to be active in a photoredox Appel-type conversion of alcohols to bromides. The catalyst was identified from a screening of 50 complexes and promoted the transformation of primary and secondary alcohols to their corresponding bromides and carboxylic acids to their anhydrides. The protocol was also amendable and optimized under continuous flow conditions.
\end{abstract}

\section{Introduction}

Synthetic photochemistry and photocatalysis continues to influence molecular synthesis [1-4]. In exploring photochemical reactivity manifolds, there exists the potential to discover new methods to construct important molecular fragments, as well as revamp traditional chemical transformations. One such process is the Appel reaction [5], which employs $\mathrm{PPh}_{3}$ and an electrophilic halogen source to promote the formation of an organic halide from the corresponding alcohol (Figure 1) [6,7]. The Appel reaction is representative of a host of transformations that require stoichiometric reagents to effect a functional group change of an alcohol. In 2011, Stephenson and co-workers re- ported that photocatalysis could be used to promote the alcohol $\rightarrow$ halide conversion using low catalyst loadings of a ruthenium-based catalyst ( $\mathrm{Ru}(\mathrm{bpy})_{3} \mathrm{Cl}_{2}, 1 \mathrm{~mol} \%$ ) in the absence of $\mathrm{PPh}_{3}$ as a reductant (Figure 1) [8]. The method possesses numerous advantages (wide functional group tolerance, no formation of oxidized phosphine byproducts [9-14], mild reaction conditions and visible-light irradiation), which should be easily embraced by the synthetic community. To further develop the photochemical alcohol $\rightarrow$ halide transformation, the use of alternative photocatalysts based upon more abundant metals was envisioned [15-18]. Specifically, our group has demon- 
past work:<smiles>[R]C([R])O</smiles><smiles>[R]C([R])O</smiles>
(Stephenson)

this work:<smiles>Br[C+](Br)CCPP[C@@]12CCCPN1CCCN2</smiles><smiles>[R]C([R])C#CC#Cc1ccc(OC([R])[R])cc1</smiles>
visible light

- heteroleptic copper-based photocatalysts

- applicability to continuous flow

Figure 1: Alcohol $\rightarrow$ bromide functional group transformations. strated that heteroleptic $\mathrm{Cu}(\mathrm{I})$ complexes [19-21] have significant potential as photocatalysts that can promote a variety of mechanistically distinct photochemical transformations including single electron transfer (SET), energy transfer (ET), and proton-coupled electron transfer (PCET) reactions [22-26]. Herein, the evaluation of $\mathrm{Cu}(\mathrm{I})$-complexes for photocatalytic Appel reactions and demonstration in continuous flow is described.

\section{Results and Discussion}

The first step in identifying a heteroleptic diamine/bisphosphine $\mathrm{Cu}(\mathrm{I})$-based photocatalyst for the conversion of an alcohol to bromide involved screening a wide variety of structurally varied complexes. Our group has previously demonstrated that the nature of each ligand influences the physical and photophysical properties as well as catalytic activity of the resulting catalyst (Figure 2) [27].

A library of 50 different catalysts was evaluated in the conversion of alcohol 1 to bromide 2 (Figure 2 and Figure 3). Several homoleptic complexes were not evaluated due to problematic

general copper-based photocatalyst structures

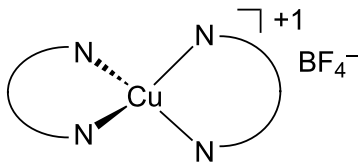

homoleptic $\mathrm{Cu}(\mathrm{I})(\text { diamine })_{2} \mathrm{BF}_{4}$

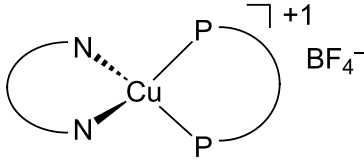

heteroleptic $\mathrm{Cu}(\mathrm{I})\left(\right.$ diamine)(biphosphine) $\mathrm{BF}_{4}$

diamine ligands:<smiles></smiles>

$\mathrm{R}^{1}=\mathrm{R}^{2}=\mathrm{R}^{3}=\mathrm{H}$ phen

$R^{1}=M e, R^{2}=R^{3}=H$ dmp

$\mathrm{R}^{1}=\mathrm{H}, \mathrm{R}^{2}=\mathrm{R}^{3}=$ Me tmp $R^{1}=R^{2}=H, R^{3}=$ Ph batho

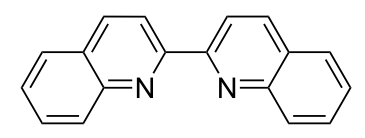

dq

$\mathrm{R}^{1}=$ OMe dmbp $\mathrm{R}^{1}=t-\mathrm{Bu} \mathbf{d t b b p}$
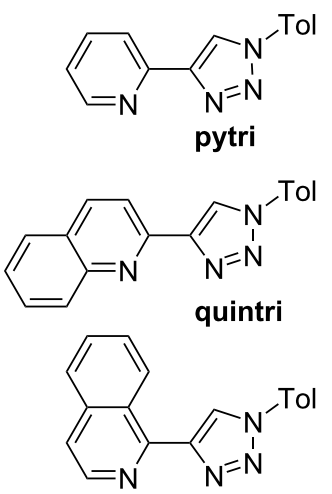

iquintri

bisphosphine ligands:<smiles>Pc1ccccc1P(c1ccccc1)c1ccccc1P</smiles>

DPEPhos<smiles>CC1(C)c2cccc(-c3ccccc3)c2Oc2c(-c3ccccc3)cccc21</smiles>

XantPhos

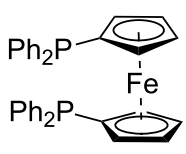

dppf<smiles>Pc1cccc(-c2c(P)ccc3ccccc23)c1P</smiles>

BINAP

Figure 2: Ligands used in the library generation of heteroleptic copper(I)-based complexes for photocatalysis. 

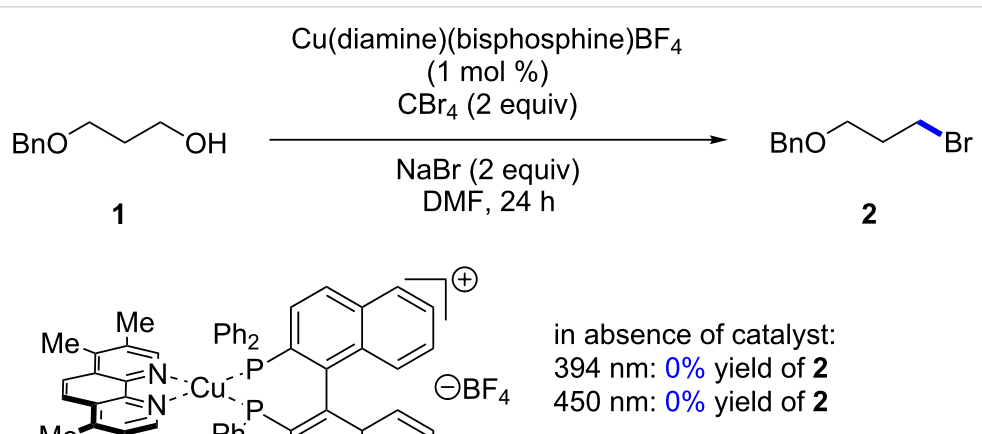

previously reported catalyst (for an analogous alcohol): optimized catalyst: $\mathrm{Cu}(\operatorname{tmp})\left(\mathrm{BINAP}_{\mathrm{B}} \mathrm{BF}_{4} 99 \%\right.$ $\mathrm{Ru}(\mathrm{bpy})_{3}(\mathrm{Cl})_{2} 96 \%$

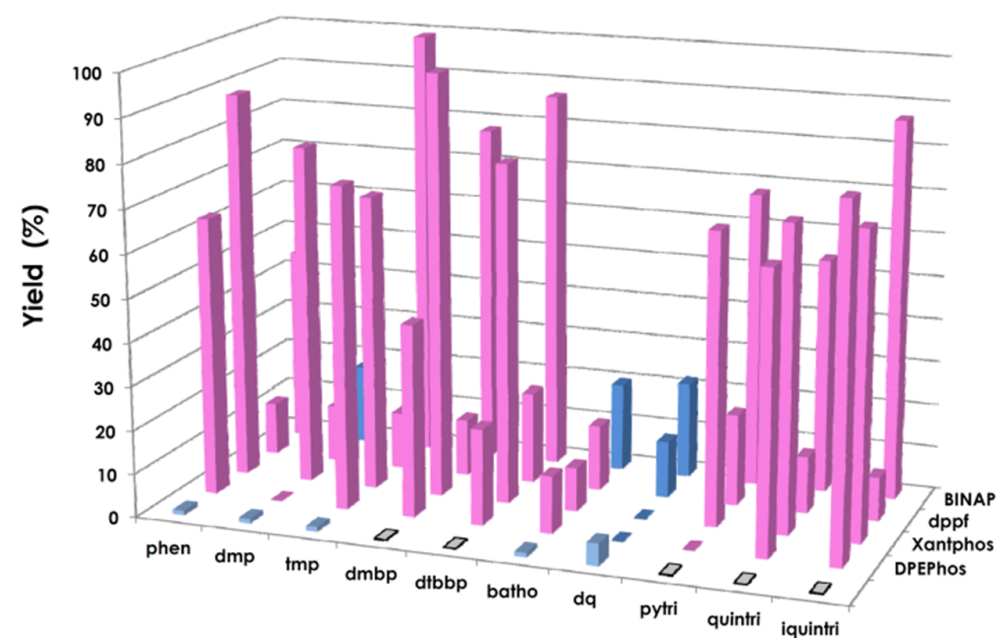

Figure 3: Evaluation of the library of copper-based complexes in photocatalytic alcohol $\rightarrow$ bromide conversion. Reactions irradiated with $394 \mathrm{~nm}$ light

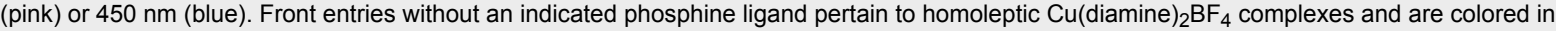
lighter blue. Entries without a color indicate reactions which could not be performed due to solubility or overoxidation of the complex.

oxidation or low solubility. Reactions were irradiated at either $394 \mathrm{~nm}$ (purple LEDs) or $450 \mathrm{~nm}$ (blue LEDs), depending on the UV-vis absorption characteristics of the photocatalysts [28]. Stephenson and co-workers had previously reported that a primary alcohol structurally similar to $\mathbf{1}$ underwent conversion to the corresponding bromide in $96 \%$ yield upon irradiation in the presence of $\mathrm{Ru}(\mathrm{bpy}){ }_{3} \mathrm{Cl}_{2}(1 \mathrm{~mol} \%)$. The screening for a suitable copper-based catalyst was performed under identical reaction conditions whereby the Ru-based photocatalyst was substituted for the $\mathrm{Cu}$-based complex. Control reactions performed in the absence of light or in the absence of catalyst at either 394 or $450 \mathrm{~nm}$ revealed no conversion to the bromide. From the results, none of the homoleptic complexes promoted the alcohol-to-halide conversion $(\mathbf{1} \rightarrow \mathbf{2}$, see the light blue entries in the front row of Figure 3). While many of the heteroleptic complexes promoted the reaction, some trends were apparent. In general, amongst the phosphines the dppf-based complexes were poor catalysts, while when considering the diamine ligands the dq and bathophenthroline catalysts provided poor to modest yields. Also, BINAP and Xantphos-based catalysts tended to afford higher yields of $\mathbf{2}$, while amongst the diamines, the triazole-based complexes were almost all efficient at providing 2 (54-87\% yield, not including dppf-based complexes). Interestingly, the best catalyst for the transformation (Cu(tmp)(BINAP)BF $4,99 \%$ of 2 ) was a poor catalyst for a previously reported photoredox reaction [27]. It should be noted that $\mathrm{Cu}(\mathrm{tmp})(\mathrm{BINAP})^{+}$possesses an excited state reduction potential of $-1.93 \mathrm{~V}$ vs. SCE, much greater than that of $\mathrm{Ru}(\text { bpy })_{3}{ }^{+2}(-0.81 \mathrm{~V}$ vs SCE), albeit the copper complex has a much shorter excited state lifetime $(\approx 4 \mathrm{~ns}$ vs $\approx 1100 \mathrm{~ns}$ for $\mathrm{Ru}(\mathrm{bpy})_{3}{ }^{+2}$ ). The excited state reduction potential should match favorably with $\mathrm{CBr}_{4}\left(E_{1 / 2}=0.30 \mathrm{~V}\right.$ vs SCE) in DMF [29]. Note that many of the corresponding homoleptic copper-based sensitizers were ineffective at promoting the Appel-type reaction.

With conditions in hand for the formation of the bromides, different alcohols were converted to their corresponding halides 
(Table 1). As shown previously, a benzyl-protected alcohol 1 could be transformed to the corresponding bromide 2 in $99 \%$ yield, respectively (Table 1, entry 1). The corresponding bromide of citronellol (4) was also formed in high yield (91\%, Table 1, entry 2). A long chain methyl ester 5 was also tolerated under the reaction conditions $(98 \%$ of the bromide Table 1, entry 3 ). The corresponding dibromide could be formed from 1,9-nonadiol (6) in quantitative yield $(99 \%$, Table 1, entry 4). A sulfur-containing alcohol 7 was smoothly converted to its bromide in $99 \%$ yield (Table 1, entry 5). An allylic alcohol 8 having a cis-olefin underwent alcohol-to-halide conversion in $89 \%$ yield and was isolated as a 1:1 mixture of cis and trans isomers (Table 1, entry 6). Finally, a racemic secondary alcohol 9 was easily transformed to the corresponding racemic bromide $(99 \%$, Table 1 , entry 7$)$.

Following the optimization of the catalyst structure and exploration of scope, the batch reaction conditions were then transferred to continuous flow (Table 2). Initially, an experimental set-up using a previously reported reactor for purple LEDs was selected for the reaction [30,31]. Following injection of the reaction mixture with a target residence time of $60 \mathrm{~min}$, only traces of the desired bromide 2 were observed. Extending the residence time to 120 or $240 \mathrm{~min}$ increased the yield to $32-53 \%$, but significant quantities of the starting alcohol 1 and the corresponding formate ester 3 were observed. Using tetra- $n$ butylammonium bromide (TBAB) as the halide source did not improve the yield, but resulted in larger amount of the formy-
Table 1: Photocatalytic conversion of alcohols to bromides in batch.

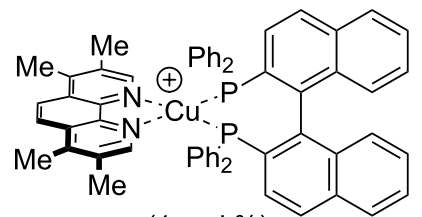
$\mathrm{BF}_{4}$ (1 $\mathrm{mol} \%)$

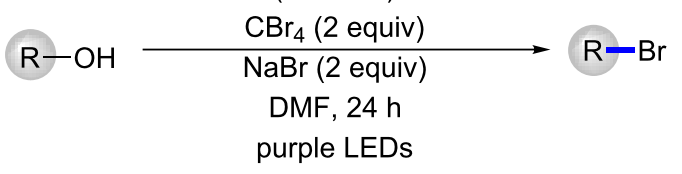

entry \begin{tabular}{c} 
yield (\%) \\
\hline 6
\end{tabular}

aYield determined by isolation via chromatography. ${ }^{\mathrm{b}}$ Isolated as a $1: 1$ mixture of cis and trans isomers.

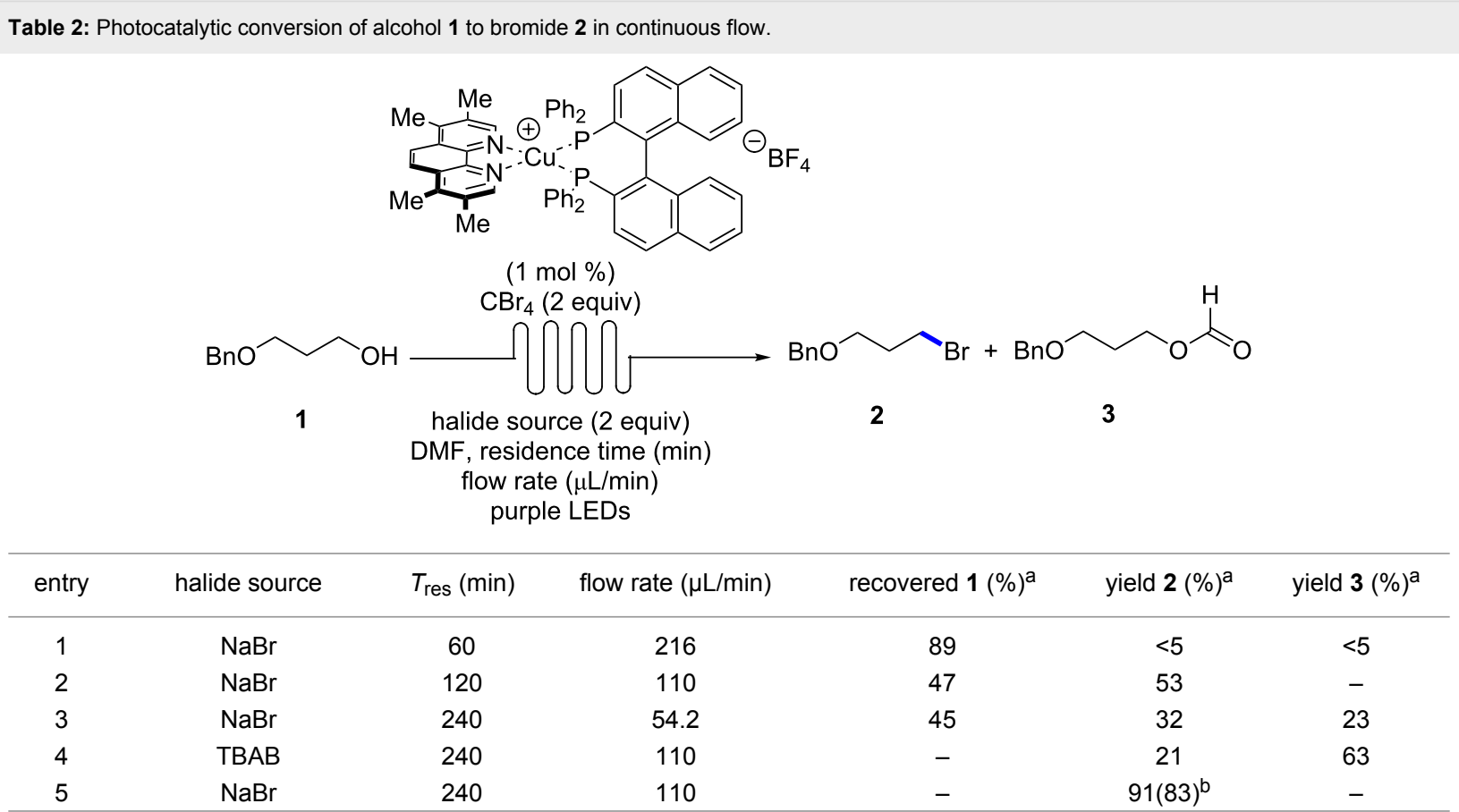

aYield determined by analysis of ${ }^{1} \mathrm{H}$ NMR. ${ }^{b}$ Yield determined by isolation via chromatography. 
lated product 3 (Table 2, entry 4). A possible explanation for the increased yield of $\mathbf{3}$ when using TBAB could be due to slower displacement of leaving group by the "bulkier" source of bromide. In attempting to extend the residence time, the flow rate of the reaction mixture was decreased. Knowing that faster flow rates can improve mixing and reaction rates [32], an additional reactor was placed in line and the residence time of $240 \mathrm{~min}$ was repeated but with an increased flow rate ( $110 \mu \mathrm{L} / \mathrm{min}$, Figure 4 and Table 2 entry 5). Gratifyingly, the desired bromide 2 was isolated in $91 \%$ yield.

With optimized flow conditions in hand for the formation of bromides in continuous flow, five different alcohols were converted to their corresponding halides (Table 3). The benzyl-protected alcohol 1 could be transformed to the bromide in $83 \%$ yield (Table 3 , entry 1 ), as was citronellol (4, 83\% yield, Table 3, entry 2). A methyl ester 5, allylic alcohol $\mathbf{8}$ and racemic secondary alcohol 9 could all undergo conversion to their corresponding bromides in $240 \mathrm{~min}$ using the continuous flow protocol (Table 3, entries 3 to 5).

The continuous flow protocol was also applicable to the synthesis of anhydrides, which has also been previously reported by Stephenson and co-workers [33]. The carboxylic acid $\mathbf{1 0}$ was submitted to a flow protocol using the optimized $\mathrm{Cu}$ (tmp)(BINAP)BF 4 catalyst, $\mathrm{CBr}_{4}$ (1 equiv) and 2,6-lutidine as base with a residence time of $20 \mathrm{~min}$ (Scheme 1). The anhydride derived from $p$-methoxybenzoic acid was isolated in $90 \%$ yield.
Table 3: Photocatalytic conversion of alcohols to bromides in continuous flow.

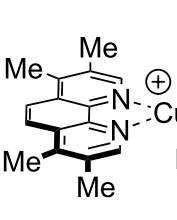

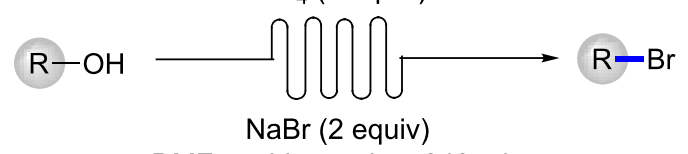

DMF, residence time $240 \mathrm{~min}$ flow rate $110 \mu \mathrm{L} / \mathrm{min}$ purple LEDs

\begin{tabular}{|c|c|c|c|}
\hline entry & alcohol & & yield $(\%)^{a}$ \\
\hline 1 & & 1 & 83 \\
\hline 2 & & 4 & 83 \\
\hline 3 & & 5 & 85 \\
\hline 4 & & 8 & 86 \\
\hline 5 & & 9 & 86 \\
\hline
\end{tabular}

aYield determined by isolation via chromatography.

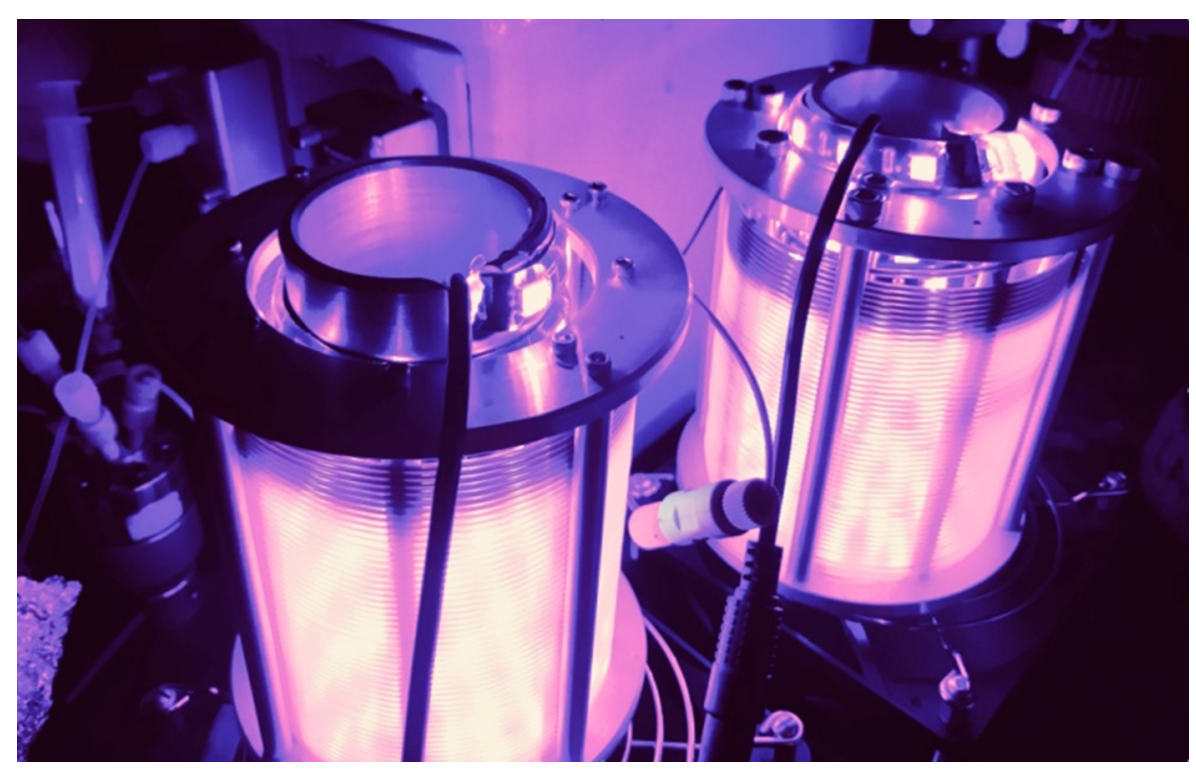

Figure 4: Experimental set-up for the photocatalytic conversion of alcohols to bromides. PFA tubing is wrapped around purple LEDs (394 nm) and fans are placed underneath reactors to maintain cooling. 


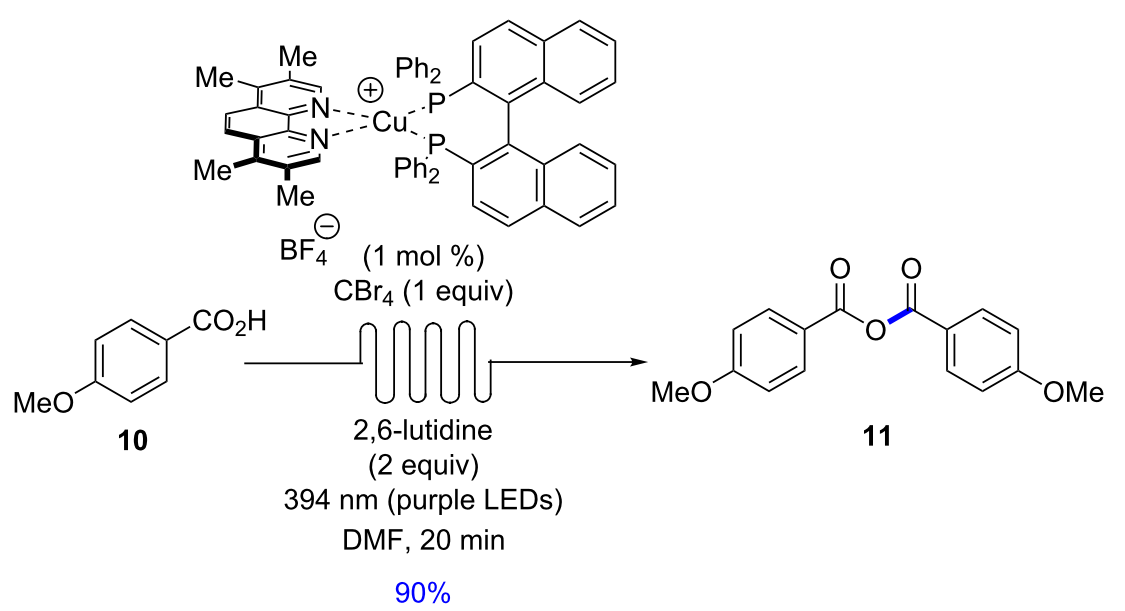

Scheme 1: Copper-based photocatalysis for photocatalytic synthesis of an anhydride.

\section{Conclusion}

In summary, a heteroleptic copper-based photocatalyst $\mathrm{Cu}(\mathrm{tmp})(\mathrm{BINAP}) \mathrm{BF}_{4}$ was discovered for the photochemical Appel-type conversion of alcohols to bromides, as well as carboxylic acids to their anhydrides. The protocol was highly efficient and could be adapted to continuous flow using purple LED reactors. The batch and continuous flow processes were all made possible due to the ability to screen highly modular copper-based complexes for photocatalysis.

\section{Supporting Information}

\section{Supporting Information File 1}

Experimental details and compound characterization. [https://www.beilstein-journals.org/bjoc/content/ supplementary/1860-5397-14-251-S1.pdf]

\section{Acknowledgements}

The authors acknowledge the Natural Sciences and Engineering Research Council of Canada (NSERC), the NSERC CREATE program in Continuous Flow Science, the Canadian Foundation for Innovation for financial support for continuous flow infrastructure and the Centre in Green Chemistry and Catalysis (CGCC) for funding. Ms. Vanessa Kairouz is thanked for assistance with the continuous flow infrastructure.

\section{ORCID ${ }^{\circledR}$ iDs}

Shawn K. Collins - https://orcid.org/0000-0001-9206-5538

\section{References}

1. Stephenson, C. R. J.; Yoon, T. P.; MacMillan, D. W. C., Eds. Visible Light Photocatalysis in Organic Chemistry; Wiley-VCH: Hoboken, New Jersey, 2018.
2. Albini, A.; Fagnoni, M., Eds. Handbook of Synthetic Photochemistry; Wiley-VCH: Germany, 2010.

3. Rackl, D.; Kreitmeier, P.; Reiser, O. Green Chem. 2016, 18, 214-219. doi:10.1039/C5GC01792K

4. Lima, C. G. S.; de M. Lima, T.; Duarte, M.; Jurberg, I. D.; Paixão, M. W. ACS Catal. 2016, 6, 1389-1407. doi:10.1021/acscatal.5b02386

5. Appel, R. Angew. Chem., Int. Ed. Engl. 1975, 14, 801-811. doi:10.1002/anie.197508011

6. Weiss, R. G.; Snyder, E. I. Chem. Commun. 1968, 1358-1359. doi:10.1039/C19680001358

7. Weiss, R. G.; Snyder, E. I. J. Org. Chem. 1971, 36, 403-406. doi:10.1021/jo00802a009

8. Dai, C.; Narayanam, J. M. R.; Stephenson, C. R. J. Nat. Chem. 2011, 3, 140-145. doi:10.1038/nchem.949

9. Larock, R. C. Comprehensive Organic Transformations, 2nd ed.; John Wiley \& Sons, 1999; p 689.

10. Fujisawa, T.; lida, S.; Sato, T. Chem. Lett. 1984, 13, 1173-1174. doi:10.1246/cl.1984.1173

11. Mukaiyama, T.; Shoda, S.-i.; Watanabe, Y. Chem. Lett. 1977, 6, 383-386. doi:10.1246/cl.1977.383

12. Benazza, T.; Uzan, R.; Beaupère, D.; Demailly, G. Tetrahedron Lett. 1992, 33, 4901-4904. doi:10.1016/S0040-4039(00)61228-5

13. Benazza, T.; Uzan, R.; Beaupère, D.; Demailly, G. Tetrahedron Lett. 1992, 33, 3129-3132. doi:10.1016/S0040-4039(00)79831-5

14. Kelly, B. D.; Lambert, T. H. J. Am. Chem. Soc. 2009, 131, 13930-13931. doi:10.1021/ja906520p

15. Zhao, Y.; Antonietti, M. ChemPhotoChem 2018, 2, 720-724. doi:10.1002/cptc. 201800084

See for an alternative route to convert alcohols to iodides in the absence of catalyst.

16. Reiser, O.; Kachkovskyi, G.; Kais, V.; Kohls, P.; Paria, S.; Pirtsch, M.; Rackl, D.; Seo, H. Chem. Photocatal. 2013, 139-150. doi:10.1515/9783110269246.139

17. Higgins, R. F.; Fatur, S. M.; Shepard, S. G.; Stevenson, S. M.; Boston, D. J.; Ferreira, E. M.; Damrauer, N. H.; Rappé, A. K.; Shores, M. P. J. Am. Chem. Soc. 2016, 138, 5451-5464. doi:10.1021/jacs.6b02723

18. Ruhl, K. E.; Rovis, T. J. Am. Chem. Soc. 2016, 138, 15527-15530. doi:10.1021/jacs.6b08792 
19. Hernandez-Perez, A. C.; Collins, S. K. Acc. Chem. Res. 2016, 49, 1557-1565. doi:10.1021/acs.accounts.6b00250

20. Hernandez-Perez, A. C.; Collins, S. K. Angew. Chem., Int. Ed. 2013, 52, 12696-12700. doi:10.1002/anie.201306920

21. Knorn, M.; Rawner, T.; Czerwieniec, R.; Reiser, O. ACS Catal. 2015, 5, 5186-5193. doi:10.1021/acscatal.5b01071

22. Beatty, J. W.; Stephenson, C. R. J. Acc. Chem. Res. 2015, 48, 1474-1484. doi:10.1021/acs.accounts.5b00068

23. Prier, C. K.; Rankic, D. A.; MacMillan, D. W. C. Chem. Rev. 2013, 113 , 5322-5363. doi:10.1021/cr300503r

24. Shaw, M. H.; Twilton, J.; MacMillan, D. W. C. J. Org. Chem. 2016, 81, 6898-6926. doi:10.1021/acs.joc.6b01449

25. Arias-Rotondo, D. M.; McCusker, J. K. Chem. Soc. Rev. 2016, 45 , 5803-5820. doi:10.1039/C6CS00526H See for energy transfer.

26. Gentry, E. C.; Knowles, R. R. Acc. Chem. Res. 2016, 49, 1546-1556. doi:10.1021/acs.accounts.6b00272 See for proton-coupled electron transfer.

27. Minozzi, C.; Caron, A.; Grenier-Petel, J.-C.; Santandrea, J.; Collins, S. K. Angew. Chem., Int. Ed. 2018, 57, 5477-5481. doi:10.1002/anie.201800144

28. See Supporting Information File 1 for tabular data on reaction yields. 29. Fukui, K.; Morokuma, K.; Kato, H.; Yonezawa, T. Bull. Chem. Soc. Jpn. 1963, 36, 217-222. doi:10.1246/bcsj.36.217

30. Parisien-Collette, S.; Cruché, C.; Abel-Snape, X.; Collins, S. K. Green Chem. 2017, 19, 4798-4803. doi:10.1039/C7GC02261A

31. Parisien-Collette, S.; Collins, S. K. ChemPhotoChem 2018, 2, 855-859. doi:10.1002/cptc.201800096

32. Cambié, D.; Bottecchia, C.; Straathof, N. J. W.; Hessel, V.; Noël, T. Chem. Rev. 2016, 116, 10276-10341. doi:10.1021/acs.chemrev.5b00707

33. Konieczynska, M. D.; Dai, C.; Stephenson, C. R. J. Org. Biomol. Chem. 2012, 10, 4509-4511. doi:10.1039/c2ob25463h

\section{License and Terms}

This is an Open Access article under the terms of the Creative Commons Attribution License (http://creativecommons.org/licenses/by/4.0). Please note that the reuse, redistribution and reproduction in particular requires that the authors and source are credited.

The license is subject to the Beilstein Journal of Organic Chemistry terms and conditions:

(https://www.beilstein-journals.org/bjoc)

The definitive version of this article is the electronic one which can be found at: $\underline{\text { doi:10.3762/bjoc. } 14.251}$ 